\section{AUTHORS:}

Dakalo C. Mashao ${ }^{1,2}$

Michael J. Kosch ${ }^{2,3,4}$ iD

Jozsef Bór $r^{5}$ iD

Stanislaus Nnadih ${ }^{6,7}$ iD

\section{AFFILIATIONS:}

'Department of Physics, University of KwaZulu-Natal, Durban, South Africa ${ }^{2}$ Space Science Division,

South African National Space Agency, Hermanus, South Africa

${ }^{3}$ Department of Physics, University

of the Western Cape, Cape Town,

South Africa

${ }^{4}$ Physics Department, Lancaster

University, Lancaster, United Kingdom ${ }^{5}$ Research Centre for Astronomy and

Earth Science, Hungarian Academy

of Science, Budapest, Hungary

${ }^{6}$ African Regional Centre for Space

Science and Technology Education,

Ile Ife, Nigeria

${ }^{7}$ Spacelab, Department of Electrical

Engineering, University of Cape Town,

Cape Town, South Africa

\section{CORRESPONDENCE TO:}

Dakalo Mashao

EMAIL:

mashaodakalo@gmail.com

\section{DATES:}

Received: 07 Feb. 2020

Revised: 12 June 2020

Accepted: 13 June 2020

Published: 29 Jan. 2021

\section{HOW TO CITE:}

Mashao DC, Kosch MJ, Bór J,

Nnadih S. The altitude of sprites

observed over South Africa. S Afr J Sci.

2021;117(1/2), Art. \#7941. https://

doi.org/10.17159/sajs.2021/7941

\section{ARTICLE INCLUDES:}

囚 Peer review

囚 $\underline{\text { Supplementary material }}$

\section{DATA AVAILABILITY:}

$\square$ Open data set

$\square$ All data included

$\otimes$ On request from author(s)

$\square$ Not available

$\square$ Not applicable

EDITOR:

Amanda Weltman (iD)

\section{KEYWORDS:}

charge moment change, lightning.

transient luminous events

\section{FUNDING:}

Hungarian National Research, Development and Innovation Office (K115836), South African National Space Agency, University of the Western Cape

(C) 2021. The Author(s). Published under a Creative Commons Attribution Licence.

\title{
The altitude of sprites observed over South Africa
}

\begin{abstract}
Sprites are mesospheric optical emissions that are mostly produced by large, positive cloud-to-ground lightning discharges. Sprites appear in different morphologies such as carrot, jellyfish and column, and are typically in the altitude range of $\sim 40-100 \mathrm{~km}$ above the Earth's surface. Sprites are a subset of transient luminous events and they contribute to the global electric circuit. South Africa has large convective thunderstorms, which typically occur in the summer months of every year. Peak current, time and geographical position of lightning strokes were obtained from the South African Weather Service. Sprite observations were recorded in South Africa for the first time on 11 January 2016 from Sutherland in the Northern Cape using a night-vision television camera from the South African National Space Agency's Optical Space Research laboratory. We report the first estimates of the top altitude, and the altitude of maximum brightness, of 48 sprites over South Africa. We found that the average top altitude and the altitude of maximum brightness of sprites are approximately $84.3 \mathrm{~km}$ and $69 \mathrm{~km}$, respectively, which is consistent with estimates made elsewhere. We also found a moderately high positive and a weak positive correlation between the top altitude and the altitude of maximum brightness, respectively, of sprites and the lightning stroke charge moment change.
\end{abstract}

\section{Significance:}

- We present the first altitude estimation of sprites observed over Africa.

- The altitude of sprites observed over South Africa is in agreement with observations made elsewhere.

- There is a positive correlation between the top altitude of sprites and the parent lightning charge moment change.

- Sprite maximum brightness is observed near the stratopause.

\section{Introduction}

Sprites are optical phenomena generated by the electric field in the mesosphere, almost exclusively during positive cloud-to-ground $(+C G)$ lightning flashes with a high peak current and a high charge moment change (CMC). Sprites play a role in the global electric circuit. ${ }^{1-3}$ The optical signature of sprite events typically lasts for about $1-10$ ms. ${ }^{2}$ However, some sprite events can last for more than $10 \mathrm{~ms}$, especially in the case of dancing sprites and column sprites which are not very bright. ${ }^{4,5}$ Sprites are the most familiar type of transient luminous events (TLEs), which are short-lived gas breakdown phenomena that occur well above the altitudes of normal lightning and storm clouds, typically $\sim 40-100 \mathrm{~km}$. Sprites, halos, elves, blue jets and gigantic jets are different types of TLEs. Sprites consist of many streamers, which are typically measure $60-200 \mathrm{~m}$ in horizontal length.

Sprites are generated by the quasi-electrostatic field generated by the large CMC from the initial lightning stroke and its subsequent continuing current during mesoscale convective system thunderstorms. This occurs when a high amount of positive charge is lowered to the ground during a lightning discharge and the opposite sign charge above the convective thundercloud creates a quasi-electrostatic field in the mesosphere. This results in heating and ionisation in the mesosphere, leading to the initiation of a streamer propagation which is observed as sprites. ${ }^{1,6,7} \mathrm{~A}$ CMC of about 120-18 $600 \mathrm{C} \mathrm{km}$ with a discharge time of approximately hundreds of microseconds has been found in the parent lightning strokes of sprites. ${ }^{1,6,8,9} \mathrm{~A} \mathrm{CMC}$ value of $1000 \mathrm{C} \mathrm{km}$ or more has a $90 \%$ chance of generating TLEs, whereas a CMC value of $600 \mathrm{C} \mathrm{km}$ or less has only a $10 \%$ chance of producing TLEs. ${ }^{6}$

The first reported sprite was recorded by chance on 6 July 1989 in the USA. ${ }^{10}$ Since then, TLE-related research has been active in many continents, for instance, the Americas, Africa, Asia and Europe..$^{1,2,4-12}$ Sprite events have been recorded from the ground and space (e.g. by the ISUAL sensor)..$^{13}$ There have been several reports on the altitude of sprites. Sentman et al. ${ }^{14}$ conducted the first sprites triangulation. They found that sprites' average top altitude was about $88 \mathrm{~km}$, with a root mean square error of approximately $5 \mathrm{~km}$. The top altitude for the largest and brightest event that they recorded occurred at about $95 \mathrm{~km}$. Wescott et al. ${ }^{15}$ investigated column sprites or c-sprites. They found that the top altitude for these sprites varied from $81.3 \mathrm{~km}$ to $88.9 \mathrm{~km}$, and the mean value of the top of the column sprites was $86.4 \mathrm{~km}$, with a standard deviation of $1.9 \mathrm{~km}$.

Stenbaek-Nielsen et al. ${ }^{16}$ found that the triangulated initiation altitude of the downward streamer of sprites ranged from $66 \mathrm{~km}$ to $89 \mathrm{~km}$ and the triangulated top of the sprites varied from $79 \mathrm{~km}$ to $96 \mathrm{~km}$. Stenbaek-Nielsen et al. ${ }^{16}$ also analysed the sprites data which they observed from one location using high-speed cameras. They assumed that the sprite occurred close to the causal lightning strike and found that onset altitude ranged from $75 \mathrm{~km}$ to 95 $\mathrm{km}$ above the Earth's surface, with an average altitude of $85 \mathrm{~km}$. The initiation altitude uncertainty of the sprite was determined to be about $1 \mathrm{~km}$, depending on the observation elevation angle. Ground-based sprite observations were conducted on the eastern coastline of the Mediterranean Sea for the first time in the winter of 2005/2006 by Ganot et al. ${ }^{17}$ They found that the average altitude of the bright transition region of sprites, measured between the diffuse region and the streamer region, was $73 \pm 10 \mathrm{~km}$ above the Earth's surface. ${ }^{17}$

Li et al..$^{18}$ reported the lightning CMC associated with long-delayed sprites. From their high camera frame rate time-resolution studies, they found that short delay $(<15 \mathrm{~ms})$ sprites initiate at an altitude of about $75-80 \mathrm{~km}$. 
A lightning $\mathrm{CMC}$ of $600 \mathrm{C} \mathrm{km}$ is required to initiate a minimum longdelayed sprite $(>15 \mathrm{~ms})$. The very long delay $(>120 \mathrm{~ms})$ sprites are initiated at an altitude of approximately $70 \mathrm{~km}$ above the Earth's surface and are associated with a minimum lightning CMC of $2000 \mathrm{C} \mathrm{km}$. McHarg et al..$^{19}$ investigated sprites' streamers at 10000 frames per second (fps) with a video frame exposure time of $50 \mu \mathrm{s}$. They found that streamers initiate at an altitude of about $82 \mathrm{~km}$ and propagate downward to about $45 \mathrm{~km}$. The upward streamers start on the sprite body at an altitude near $75 \mathrm{~km}$ and propagate up to $95 \mathrm{~km} .{ }^{19}$

Sprites were recorded for the first time in South Africa on 11 January 2016 by Nnadih et al. ${ }^{12}$ This work is aimed at characterising the altitude of these sprites observed over South Africa.

\section{Observations and measurements}

All the sprites reported here were recorded from the South African Astronomical Observatory (SAAO) in Sutherland, Northern Cape, South Africa $\left(20.81^{\circ} \mathrm{E}, 32.39^{\circ} \mathrm{S}\right)$. SAAO is located at an altitude of $\sim 1781$ $\mathrm{m}$. Observations were made at SAAO because it is at high altitude in the desert and is free from air and light pollution, which allows the observer to record any TLE occurring within a radius of $900 \mathrm{~km}$.

The observations were made during the high thunderstorm season in South Africa, which is from December to February every year. Although there was a lot of thunderstorm activity during the study, on most nights it was impossible to observe TLEs due to high local humidity, which makes it harder for a camera to detect TLE events, and local cloudy weather around SAAO, which obscures the camera's vision of distant clouds at a range of about $100-900 \mathrm{~km}$. At times the thunderstorm was too close $(<100 \mathrm{~km})$ and at other times too far $(>900 \mathrm{~km})$ from the observation site to observe TLEs. ${ }^{12}$

The sprite videos were acquired using a Watec $910 \mathrm{Hx}$ camera together with a computer system. ${ }^{12}$ The Watec $910 \mathrm{Hx}$ camera is a night-vision (sensitivity threshold of 0.64 milli-Lux), monochromatic, low-light level charge-coupled device television camera, which has been used worldwide to observe TLEs. $8,16,20-22$ The $8.0 \mathrm{~mm} \mathrm{f} / 1.4 \mathrm{C}$-mount lens provided a field of view (FOV) of $35.3^{\circ}$ horizontal and $26.6^{\circ}$ vertical. The camera FOV and pointing direction were ascertained using background stars in the sprite video clips. The observation system captured the videos at $25 \mathrm{fps}$ (frame period $=40 \mathrm{~ms}$ ) with an image size of $352 \times 288$ pixels, and an angular resolution of $0.10 / 0.09 \%$ pixel horizontal/vertical, and was operated with 8-bit intensity resolution.

The Watec $910 \mathrm{Hx}$ camera was connected to the computer via a video digitiser. The computer ran UFO-capture software version 2 (http:// sonotaco.com/soft/e index.html), which analyses the camera data in near real-time and detects all events with a detection threshold set by the operator. The UFO-capture software records a video clip for a few seconds from before until a few seconds after the triggering event. The UFO-capture software displays the time and date on the video screen. The computer was connected to the Network Timing Protocol server of SAAO, to ensure that the time was accurate $(<1 \mathrm{~ms})$. The camera viewing direction was approximately northeast of SAAO. ${ }^{12}$

The sprite observations reported here were observed from 18:43:12.0 until 21:38:06.5 UTC. Approximately 100 optical sprite events were observed during the study. However, of these, only 48 sprite events, for which the parent +CG lightning position information was available, were analysed to obtain altitude information (see Table 1). These $\sim 100$ sprites were classified as carrot (55\%), carrot and column together (clustered sprites) $(17 \%)$, column $(13 \%)$, jellyfish $(3 \%)$, unclassified $(11 \%)$, and sprite halo $(1 \%)$ as reported by Nnadih et al. ${ }^{12}$ The 48 sprites analysed were categorised as carrot $(37.5 \%)$, column $(14.6 \%)$, clustered $(25 \%)$, jellyfish $(6.3 \%)$, unclassified sprites $(14.6 \%)$ and sprite halo (2\%). We did not observe any dancing sprites.

The lightning data were provided by the South African Weather Service (SAWS). The SAWS have 23 sensors located over the entire country. The SAWS sensors detect the cloud-to-ground lightning electromagnetic signals at very low frequency $(1-10 \mathrm{kHz})$ and low frequency $(100 \mathrm{kHz})$. The network systems use magnetic direction finding and time of arrival methods to find the angle between the sensor and lightning strike and to find the lightning geographical coordinates. ${ }^{12,23}$
Extremely low frequency signals recorded at the Schumann resonance station, located at Nagycenk Observatory $\left(47.62^{\circ} \mathrm{N}, 16.72^{\circ} \mathrm{E}\right)$, Central Europe, were used to confirm the polarity and estimate the CMC of the sprite parent lightning strokes. The Nagycenk Observatory is approximately $9000 \mathrm{~km}$ to the north from SAAO. The vertical electric and the two horizontal magnetic components of the atmospheric electromagnetic field in the $\sim 3-30 \mathrm{~Hz}$ band are measured by a Schumann resonance monitoring system. Estimation of the CMC values used in this work is described in more detail by Nnadih et al. ${ }^{12}$

\section{Observation technique and data analysis}

The altitude of sprites was determined from their ground distance and elevation angle from the observation site. The ground distance to the projection of the sprites to the Earth's surface was assumed to be the distance to the parent lightning stroke. The elevation angle was obtained from the captured video by determining the exact pointing direction of the camera and then the direction of selected pixels of the sprite (see Supplementary appendix 1). A detailed description of the observation technique is given in Nnadih et al. ${ }^{12}$

\section{Finding the direction of sprites}

The azimuth and elevation angle of objects in the image and FOV of the camera can be obtained by recognising the stars in the background of a recorded image. This was achieved using the Stellarium software version 0.17 (https://stellarium.org/).

Knowing the stars' right ascension and declination from the star almanac, the time and camera location were used to calculate the stars' azimuth and elevation angles (see Supplementary appendix 1) within the image, plot the stars on the sprite image background and determine the camera FOV and pointing direction as well as the top altitude and maximum brightness altitude of the sprites (see Figure 1). The Python programming language was used to calculate the stars' azimuth and elevation angles from first principles (see Supplementary appendix 1) and plot the stars on the sprite image background. The calculated starfield can be manually adjusted within the image until a good fit is found to within one pixel. For the narrow FOV used, lens distortion did not need to be compensated for. However, atmospheric refraction was taken into account as described in Supplementary appendix $1 .{ }^{24}$ The star fit allows the unique conversion of the image's pixel positions to azimuth and elevation angles. The video frame timestamp and the sprite image azimuth were used to identify the parent lightning from the SAWS lightning data. In addition, the large +CG lightning strikes required to initiate most sprites occur relatively rarely and are easily identified.

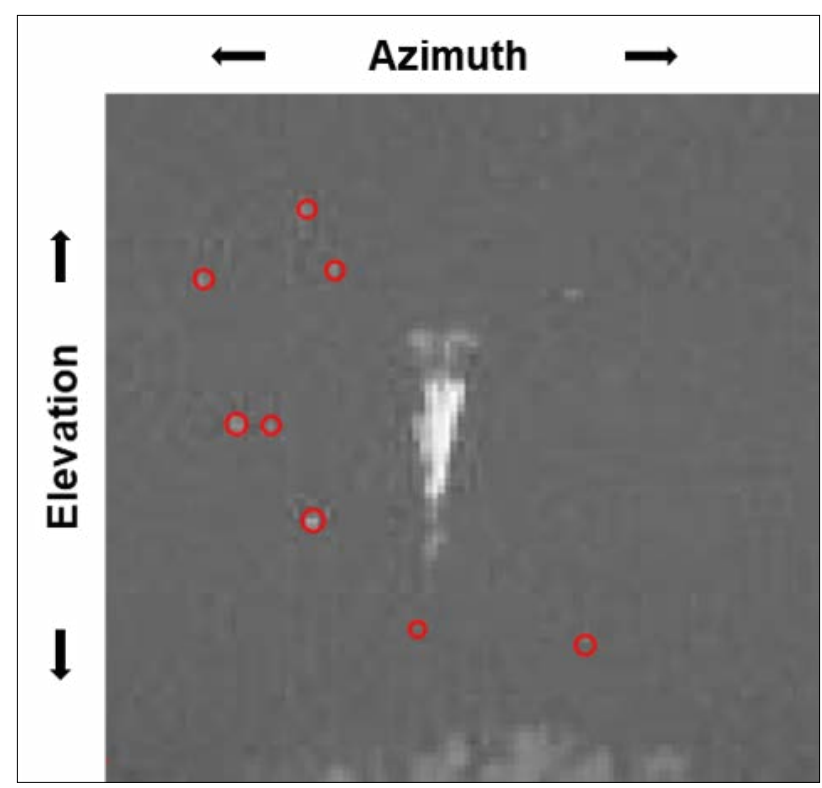

Figure 1: Sprite image with star fitting recorded on 11 January 2016 at 18:53:49.4 UTC at the South African Astronomical Observatory in Sutherland, South Africa. Red dots are the fitted stars. 


\section{Estimation of altitude}

In order to estimate the altitude of a sprite, we applied spherical trigonometry in the horizontal plane and planar trigonometry in the vertical plane to determine the top altitude and the altitude of maximum brightness of sprites $^{25}$ (see Supplementary appendix 1). Equations 1 and 2 were used to determine the slant distance to a sprite (Equation 1) and the altitude of a sprite (Equation 2) (Figure 2).

$$
r=\frac{2 R_{E} \sin (\theta)+\sqrt{4 R_{E}^{2} \sin ^{2}(\theta)+4\left[\frac{\cos ^{2}(\theta)-\sin ^{2}(A)}{\sin ^{2}(A)}\right] R_{E}^{2}}}{2\left[\frac{\cos ^{2}(\theta)-\sin ^{2}(A)}{\sin ^{2}(A)}\right]}
$$

$$
h=\left[\frac{2 R_{E} \sin (\theta)+\sqrt{4 R_{E}^{2} \sin ^{2}(\theta)+4\left[\frac{\cos ^{2}(\theta)-\sin ^{2}(A)}{\sin ^{2}(A)}\right] R_{E}^{2}}}{2\left[\frac{\cos ^{2}(\theta)-\sin ^{2}(A)}{\sin (A)}\right]}\right] \cos (\theta)-R_{E}
$$

Equation 2

where $R_{E}$ is the radius of the Earth, $r$ is the slant distance to a sprite, $h$ is the altitude of a sprite, $\theta$ is the elevation angle of a sprite from the camera position, and $A$ is the great circle angular range.

In order to determine the altitude of the sprite from single-camera observations, we assumed that the sprite occurs directly above the parent lightning strike, whose location is known from the SAWS lightning data. ${ }^{23}$ Most of the observed sprite elements were associated with a single lightning stroke, based on the time and position data. The observed sprite events without parent lightning information and those which were of unclear origin were not considered for the altitude analysis. We analysed the sprite videos frame by frame because it is possible to have more than one lightning strike and sprite event within one $40 \mathrm{~ms}$ video frame. ${ }^{12}$

In cases in which the parent lightning initiated several sprite elements, we determined the top altitude and the altitude of maximum brightness of the first sprite element in the video frame. Where possible, the first sprite was identified by analysing the sprite initiation and subsequent development over several video frames. Sprite events for which we could not tell which sprite element initiated first were not included in the altitude analysis. In cases in which sprite elements generated by two lightning strokes appeared in one video frame, based on the lightning's latitude and longitude and the elevation and azimuth angle of the sprites in the video frame, we were able to determine which lightning strike initiated a certain sprite event. The azimuth angle of the lightning and sprites within the camera's FOV usually provide a clear indication of whether the lightning initiated the sprites or not, i.e. similar lightning and sprite azimuth angles in the same image frame imply association and vice versa.

Although there is evidence that sprites can be displaced horizontally from the parent lightning strike ${ }^{14-16,26}$, our assumption that they are colocated is reasonable because there is evidence (optical observations) of sprites occurring over the parent lightning ${ }^{15,16}$. However, the most probable production mechanism for sprites suggests that in fact there is a horizontal displacement in most of the cases (typically up to $21 \mathrm{~km}$ ). ${ }^{27,28}$ A shift of tens of kilometres is small in comparison to the camera-sprite distance of $\sim 440-890 \mathrm{~km}$ in our data set, so the displacement effect is small and would affect only the calculations along the radial line of sight from the point of observation.

\section{Error analysis}

The uncertainty in the estimation of altitude depends on the luminosity limit of the camera and the accuracy of the star fitting, which affects the sprite elevation angle estimation. ${ }^{15,16}$ The uncertainty of the estimate of altitude also depends on the distance from the sprite to the observer. The angular resolution for the camera used during the study was $0.10 / 0.09 \%$ pixel horizontal/vertical, respectively, which implies that one pixel is approximately $0.1^{\circ} .{ }^{19}$ This value is comparable to that used by StenbaekNielsen et al. ${ }^{16}$ in their triangulation study of sprites.

In order to obtain the top altitude of a sprite and the altitude of maximum brightness of a sprite on a calibrated sprite image, we selected a point on the sprite to obtain the elevation angle and used Equation 2 to calculate the altitude. The pixel corresponding to the top altitude of the sprite is the pixel of greatest elevation angle within the sprite that has an intensity value greater than the background intensity for the same azimuth angle.
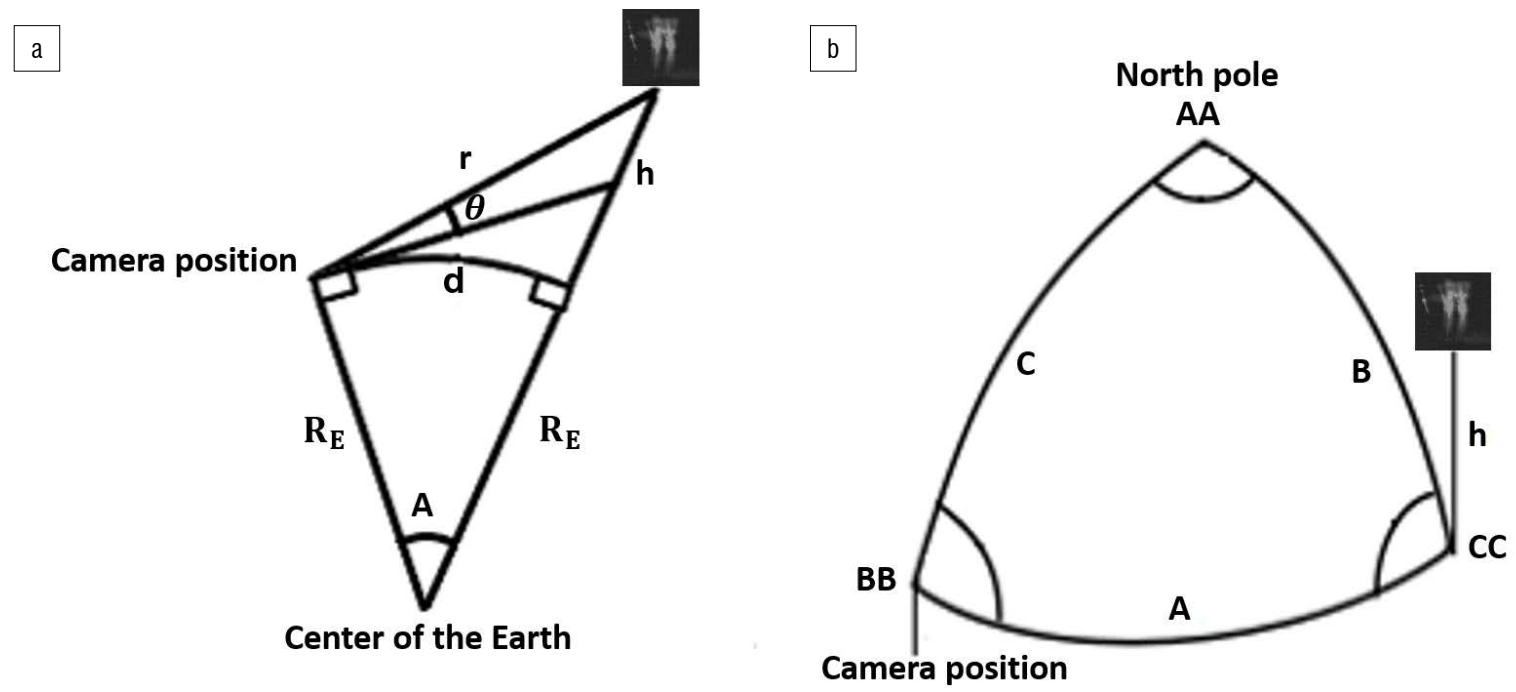

$d=$ great circle range; $R_{E}=$ radius of the Earth; $r=$ slant distance to a sprite; $h=$ altitude of a sprite; $\theta=$ elevation angle of a sprite from the camera position; $B=$ co-latitude of sprite; $C=$ co-latitude of the camera; $A A=$ change in longitude between sprite and camera position; $B B=$ azimuth angle of a sprite from the camera position; $A=$ great circle range on the ground over the radius

Figure 2: Schematic representation of basic triangles on a sphere: (a) altitude of the sprite vertical axis and (b) horizontal axes. 
The altitude of maximum brightness of a sprite was determined by identifying the brightest pixel within a sprite image..$^{29}$ This was done by sampling all the pixels within the sprite. The altitude error was obtained by calculating the altitude of two points $0.1^{\circ}$ (one pixel) above and below the point used to determine the target altitude. The change in altitude was then determined with respect to the top altitude and the altitude of maximum brightness of the sprite. This change in altitude depends on the slant distance from the top altitude or altitude of maximum brightness of the sprite to the camera $(r)$.

The sprite events we observed did not saturate the camera's detector because of the settings used, therefore we were able to determine the elevation angle corresponding to the top altitude and altitude of maximum brightness sprite pixel to an accuracy of one pixel. The time delay between the parent lightning and the sprites cannot be measured to better than $40 \mathrm{~ms}$, i.e. one video frame, the best optical time resolution available. Therefore, for our temporal resolution, we could not determine a time delay between the sprite and the parent lightning strike.

\section{Results}

The 48 sprites analysed consisted of 18 carrot, 7 column, 12 clustered (carrot and column), 3 jellyfish and 7 unclassified sprites as well as 1 sprite halo. From the SAWS lightning data, all observed sprite events were produced by $+C G$ lightning strikes with a peak current magnitude varying from $11 \mathrm{kA}$ to $191 \mathrm{kA} .{ }^{12}$

The star fitting revealed that the sprite image axes azimuth and elevation angles ranged over $30.5-65.8^{\circ}$ and $0.1-26.7^{\circ}$, respectively. The slant distance from the observer's location to the top altitude of the 48 sprite event locations was found to be $439.93-898.02 \mathrm{~km}$, giving an altitude error estimate of $\pm 0.35-0.8 \mathrm{~km}$, respectively, for one-pixel accuracy. The slant distance from the observer's location to the altitude of maximum brightness of the 48 sprite event locations was found to be $437.02-896.0 \mathrm{~km}$, giving an altitude error estimate of $\pm 0.29-0.74 \mathrm{~km}$, respectively (see Table 1), again for one-pixel accuracy. Repeating the analyses for two-pixel accuracy increases the altitude estimate by about $0.8 \mathrm{~km}$ and the altitude uncertainty to $\pm 0.8-1.5 \mathrm{~km}$. These findings are consistent with those of Stenbaek-Nielsen et al. ${ }^{16}$

\section{Distribution of top sprite altitudes}

Figure 3 shows the 48 sprites' top altitude determined through Equation 2 with respect to the time at which they occurred. The different sprite morphologies are denoted by different colours in Figure 3.

The top altitude of the sprites indicates the altitude at which the strength of the electric field in the given sprite is above a particular level, which is generally lower than the critical breakdown electric field at that altitude. ${ }^{1,30}$ From our analysis, we found that the top altitude of sprites ranged from $73.6 \mathrm{~km}$ to $95.6 \mathrm{~km}$ above the Earth's surface. The sprites' top altitude is not static; however, it does not depend on the time at which they occurred. The average top altitude of sprites was found to be approximately $84.3 \mathrm{~km}$ with a standard deviation of $5.5 \mathrm{~km}$. The average top altitudes for column, carrot, clustered, jellyfish and unclassified sprites were found to be about $83.2,84,86,90.7$ and $82 \mathrm{~km}$, with the standard deviation of $6.0,5.5,4.2,2.1$ and $6.4 \mathrm{~km}$, respectively. Our results are consistent with the reports of Sentman et al..$^{14}$ and StenbaekNielsen et al..$^{16}$ and the top altitude of column and carrot sprites reported by Wescott et al. ${ }^{15}$ and $\mathrm{Bor}^{31}$.

\section{Distribution of the altitudes of maximum sprite brightness}

The altitudes of maximum brightness for the 48 sprites are shown in Figure 4. The altitude of the maximum brightness of sprites is that at which the photon production maximises. This region has low conductivity, and the electrons are converted to negative ions which intensifies the electric field and maximises photon production. ${ }^{32}$ From our analysis, we found that the altitude of maximum brightness ranges between $53.5 \mathrm{~km}$ and $84.1 \mathrm{~km}$. The average maximum brightness altitude was found to be about $69 \mathrm{~km}$ with a standard deviation of $6.2 \mathrm{~km}$. These results are consistent with those of Luque et al. ${ }^{30}$ The average altitudes of maximum brightness for column, carrot, clustered, jellyfish and unclassified sprites were found to be about $67.4,67.3,70$, 74.3 and $73.3 \mathrm{~km}$, with corresponding standard deviations of $7.6,6.0$, $7.7,1.2$ and $4.4 \mathrm{~km}$, respectively. The altitudes of maximum brightness for column and carrot sprites are in agreement with those reported in the literature. ${ }^{15,31,32}$

The altitude of maximum brightness also does not depend on the time of the event. From the literature, the altitude of maximum brightness region lies between $65 \mathrm{~km}$ and $85 \mathrm{~km} \cdot 1,14,33$ However, we found that some sprites have a maximum brightness altitude lower than $65 \mathrm{~km}$ above the Earth's surface, with the lowest observed being at $53.5 \mathrm{~km}$, which is consistent with Füllekrug et al.' ${ }^{34}$ findings. These results therefore suggest that the photon production maximises at an altitude range of about 53.5-84.1 km, with an average of $69 \mathrm{~km}$.

\section{Sprite altitude versus charge moment change}

From Schumann resonance observations $s^{4,35,36}$ we were able to compute the lightning CMC values associated with 9 of the 48 sprites (Table 1). Figure 5 shows the lightning CMC values associated with these nine sprite events plotted against the top altitude. The +CG lightning strikes, which initiated sprites with a top altitude ranging from $83.7 \mathrm{~km}$ to 92.0 $\mathrm{km}$, yielded a CMC ranging from $900 \mathrm{C} \mathrm{km}$ to $2100 \mathrm{C} \mathrm{km}$. There is a positive correlation (correlation coefficient of 0.6 ) between the estimated top altitude of sprites and lightning CMC. ${ }^{37}$ For the altitude of maximum brightness versus CMC (not shown), there is a moderate positive correlation (correlation coefficient of 0.38). This data set is small and therefore more data are needed to reliably confirm the inferred trend.

\section{Conclusions}

Our analysis of the top altitudes and altitudes of maximum brightness of sprites recorded for the first time in South Africa shows good agreement with previous sprite observations reported in the literature.

The average estimated top altitude for the 48 sprites analysed is approximately $84.3 \mathrm{~km}$ with a standard deviation of about $5.5 \mathrm{~km}$. The top altitude of those 48 sprites ranged from $73.6 \mathrm{~km}$ to $95.6 \mathrm{~km}$. The top altitude uncertainty was found to vary from $\pm 0.35 \mathrm{~km}$ to 0.8 $\mathrm{km}$, depending on the slant distance from the observer site to the top of the sprite, which was found to be between approximately $440 \mathrm{~km}$ and $898 \mathrm{~km}$.

The maximum brightness region of sprites was found to be in the altitude range of about $53.5-84.1 \mathrm{~km}$. The average altitude of maximum brightness was approximately $69 \mathrm{~km}$, with a standard deviation of $6.2 \mathrm{~km}$. The slant distance to the maximum brightness part of the sprite from the observer site ranged from approximately $437 \mathrm{~km}$ to $896 \mathrm{~km}$ and the altitude uncertainty was found to vary from $\pm 0.29 \mathrm{~km}$ to $0.74 \mathrm{~km}$.

The linear correlation between the estimated top altitude of sprites and lightning $\mathrm{CMC}$ is equal to 0.6 and may be regarded as a moderately high correlation, although the data set is limited. A moderate correlation of 0.38 exists between the altitude of maximum brightness of sprites and the lightning CMC.

\section{Acknowledgements}

D.C.M. is grateful to the South African National Space Agency and the University of the Western Cape for the support they provided. We thank the South African Weather Service for their assistance in providing the cloud-to-ground lightning activity data. We also thank the South African Astronomical Observatory for allowing the sprites campaign team to conduct the study at their facility in Sutherland, Northern Cape Province, South Africa. The contribution of J.B. was supported by the National Research, Development and Innovation Office, Hungary-NKFIH, K115836. J.B. also appreciates the support of COST Action CA15211, ELECTRONET, in facilitating scientific communication.

\section{Competing interests}

We declare that there are no competing interests. 
Table 1: Sprite initiation time (coordinated universal time; UTC), lightning location, lightning peak current, distances, sprites' top altitude and altitude of maximum brightness. Lightning data were provided by the South African Weather Service. The charge moment change (CMC) data were computed from the Schumann resonance station at the Nagycenk Observatory, Hungary $\left(47.62^{\circ} \mathrm{N}, 16.72^{\circ} \mathrm{E}\right)$. The sprites' top altitudes and altitudes of maximum brightness were estimated as described in the text.

\begin{tabular}{|c|c|c|c|c|c|c|c|c|c|}
\hline $\begin{array}{l}\text { Sprite initiation } \\
\text { time (UTC) } \\
( \pm 20 \mathrm{~ms})\end{array}$ & $\begin{array}{l}\text { Longitude } \\
\left({ }^{\circ}\right)\end{array}$ & $\begin{array}{c}\text { Latitude } \\
\left({ }^{\circ}\right)\end{array}$ & $\begin{array}{l}\text { Peak } \\
\text { current } \\
(\mathrm{kA})\end{array}$ & $\begin{array}{l}\text { Distance from } \\
\text { the camera to } \\
\text { the lightning } \\
\text { location } \\
\text { (km) }\end{array}$ & $\begin{array}{l}\text { Slant distance } \\
\text { from the camera } \\
\text { to the top altitude } \\
(\mathrm{km})\end{array}$ & $\begin{array}{l}\text { Slant distance } \\
\text { from the camera } \\
\text { to the maximum } \\
\text { brightness } \\
\text { (km) }\end{array}$ & $\begin{array}{l}\text { Top altitude } \\
\text { of sprite } \\
\text { (km) }\end{array}$ & $\begin{array}{l}\text { Altitude of } \\
\text { maximum } \\
\text { brightness of } \\
\text { sprite } \\
\text { (km) }\end{array}$ & $\begin{array}{l}\text { CMC } \\
\text { (C km) }\end{array}$ \\
\hline 18:53:49.4 & 25.34 & -31.82 & 37 & 432.18 & 439.93 & 437.02 & 80.2 & 68.8 & \\
\hline $18: 59: 10.5$ & 25.55 & -31.90 & 82 & 450.25 & 458.52 & 456.94 & 76.3 & 68.2 & \\
\hline 19:10:04.6 & 24.71 & -27.94 & 58 & 619.94 & 629.36 & 628.17 & 79.2 & 76.3 & \\
\hline $19: 12: 54.9$ & 24.32 & -28.51 & 29 & 546.42 & 556.63 & 553.88 & 82.3 & 67.1 & \\
\hline 19:17:09.8 & 24.63 & -28.31 & 23 & 582.53 & 613.27 & 612.43 & 76.4 & 73.1 & \\
\hline 19:17:09.8 & 24.42 & -28.17 & 46 & 582.56 & 591.54 & 590.93 & 76.6 & 72 & \\
\hline 19:17:09.8 & 24.76 & -28.15 & 23 & 604.36 & 592.27 & 588.39 & 88.9 & 65 & \\
\hline $19: 22: 25.3$ & 24.02 & -28.52 & 97 & 528.24 & 537.97 & 533.24 & 83.1 & 55.1 & 1600 \\
\hline $19: 23: 10.2$ & 23.38 & -28.12 & 51 & 534.03 & 545.29 & 541.29 & 89.5 & 70 & \\
\hline $19: 28: 34.2$ & 24.65 & -27.62 & 35 & 645.51 & 654.88 & 651.84 & 91.3 & 83.5 & \\
\hline $19: 28: 34.2$ & 24.65 & -27.62 & 55 & 645.51 & 654.84 & 654.34 & 91.5 & 74.4 & \\
\hline $19: 28: 34.2$ & 23.44 & -28.30 & 69 & 519.11 & 582.98 & 581.36 & 80.5 & 72.9 & \\
\hline $19: 33: 24.0$ & 24.79 & -27.88 & 189 & 629.97 & 639.88 & 637.94 & 81.5 & 70.2 & \\
\hline $19: 34: 46.6$ & 23.79 & -27.44 & 55 & 619.51 & 629.27 & 627.71 & 88 & 79 & \\
\hline 19:36:07.3 & 24.24 & -28.23 & 72 & 566.94 & 577.77 & 575.56 & 83.2 & 71.6 & \\
\hline $19: 38: 32.5$ & 23.55 & -27.54 & 48 & 599.09 & 609.11 & 606.11 & 87.2 & 72.9 & 1000 \\
\hline $19: 48: 05.3$ & 25.14 & -28.22 & 47 & 622.09 & 629.84 & 627.4 & 79.2 & 76.5 & \\
\hline $19: 48: 05.3$ & 25.03 & -27.70 & 93 & 660.1 & 669.78 & 667.5 & 90.1 & 74.5 & \\
\hline $19: 49: 19.7$ & 24.09 & -28.00 & 56 & 580.08 & 589.07 & 587.3 & 79.6 & 74.9 & 1500 \\
\hline $19: 49: 54.3$ & 27.04 & -27.48 & 57 & 810.87 & 818 & 815 & 84.8 & 65 & \\
\hline $19: 52: 23.9$ & 24.08 & -28.26 & 87 & 555.36 & 566.49 & 561.72 & 86.9 & 66.5 & \\
\hline $19: 52: 35.4$ & 26.98 & -27.62 & 74 & 795.91 & 834.33 & 830.56 & 85.6 & 62.7 & \\
\hline 19:55:08.1 & 24.49 & -27.69 & 17 & 630.3 & 639.6 & 637.84 & 78.9 & 68.5 & \\
\hline 19:55:08.1 & 24.46 & -27.54 & 91 & 642.66 & 652.67 & 651.2 & 82.6 & 74.3 & \\
\hline 19:58:01.3 & 27.05 & -27.68 & 42 & 796.46 & 804.83 & 802.27 & 79.2 & 62 & \\
\hline 19:58:29.6 & 25.12 & -27.69 & 11 & 666.36 & 677.84 & 676.58 & 90.8 & 84.1 & 1800 \\
\hline $20: 00: 32.6$ & 26.72 & -27.31 & 37 & 801.72 & 811.45 & 807.02 & 82.8 & 53.5 & \\
\hline 20:08:03.3 & 23.94 & -28.24 & 88 & 549.73 & 559.35 & 557.9 & 77.4 & 69.5 & \\
\hline $20: 09: 25.3$ & 23.63 & -27.91 & 71 & 566.02 & 577.54 & 574.24 & 87.9 & 70.2 & 1200 \\
\hline 20:10:04.9 & 24.66 & -28.18 & 90 & 595.72 & 605.56 & 601.92 & 82.1 & 60.7 & \\
\hline $20: 10: 04.9$ & 23.96 & -28.26 & 101 & 548.91 & 558.89 & 555.68 & 80.6 & 62.4 & \\
\hline $20: 14: 02.3$ & 24.63 & -27.28 & 105 & 675.99 & 684.63 & 683.52 & 73.6 & 66.5 & \\
\hline $20: 16: 22.7$ & 27.08 & -27.67 & 26 & 799.39 & 807.52 & 805.13 & 77 & 60.8 & \\
\hline $20: 18: 46.4$ & 24.84 & -28.06 & 104 & 617.07 & 628.7 & 624.72 & 92.2 & 69.9 & 2000 \\
\hline $20: 22: 27.6$ & 23.94 & -28.26 & 33 & 547.86 & 558.64 & 555.89 & 84.9 & 69.9 & \\
\hline $20: 24: 43.7$ & 24.64 & -27.56 & 191 & 650.48 & 661.22 & 658.63 & 86.4 & 71.2 & \\
\hline $20: 26: 21.9$ & 27.57 & -27.55 & 117 & 844.34 & 854.19 & 851.76 & 88.3 & 73.1 & \\
\hline $20: 27: 34.6$ & 24.64 & -27.43 & 20 & 662.52 & 674.98 & 670.55 & 95.6 & 70.2 & \\
\hline $20: 29: 53.8$ & 24.66 & -27.51 & 126 & 656.19 & 668.04 & 663.56 & 92.3 & 75.5 & 2000 \\
\hline $20: 33: 19.2$ & 23.95 & -27.56 & 101 & 615.14 & 626.6 & 621.82 & 88.3 & 59.7 & \\
\hline $20: 38: 43.4$ & 27.43 & -27.57 & 85 & 832.49 & 841.36 & 840.28 & 82.1 & 75.2 & \\
\hline $20: 46: 42.0$ & 27.78 & -27.92 & 80 & 834.15 & 834 & 832.52 & 76.3 & 62.2 & \\
\hline $20: 46: 42.0$ & 27.73 & -27.97 & 87 & 826.86 & 843.2 & 838.68 & 84.8 & 62.7 & \\
\hline 21:01:08.0 & 23.91 & -26.40 & 48 & 728.84 & 741.02 & 736.37 & 91.7 & 62.6 & \\
\hline $21: 29: 05.4$ & 25.01 & -26.73 & 46 & 747.66 & 757.78 & 755.79 & 83.7 & 71.2 & 900 \\
\hline $21: 33: 48.1$ & 25.09 & -26.74 & 159 & 750.97 & 761.15 & 759.38 & 83.1 & 72.1 & \\
\hline $21: 38: 06.0$ & 27.42 & -26.83 & 31 & 888.26 & 898.02 & 896 & 91.6 & 72.7 & \\
\hline $21: 41: 24.3$ & 27.70 & -27.44 & 117 & 862.04 & 872.53 & 869.85 & 92 & 75.6 & 2100 \\
\hline \multicolumn{2}{|l|}{ Average altitude } & \multicolumn{3}{|l|}{84.3} & \multicolumn{2}{|l|}{69} & & & \\
\hline \multicolumn{2}{|l|}{ Standard deviation } & \multicolumn{3}{|l|}{5.5} & \multicolumn{2}{|l|}{6.2} & & & \\
\hline
\end{tabular}




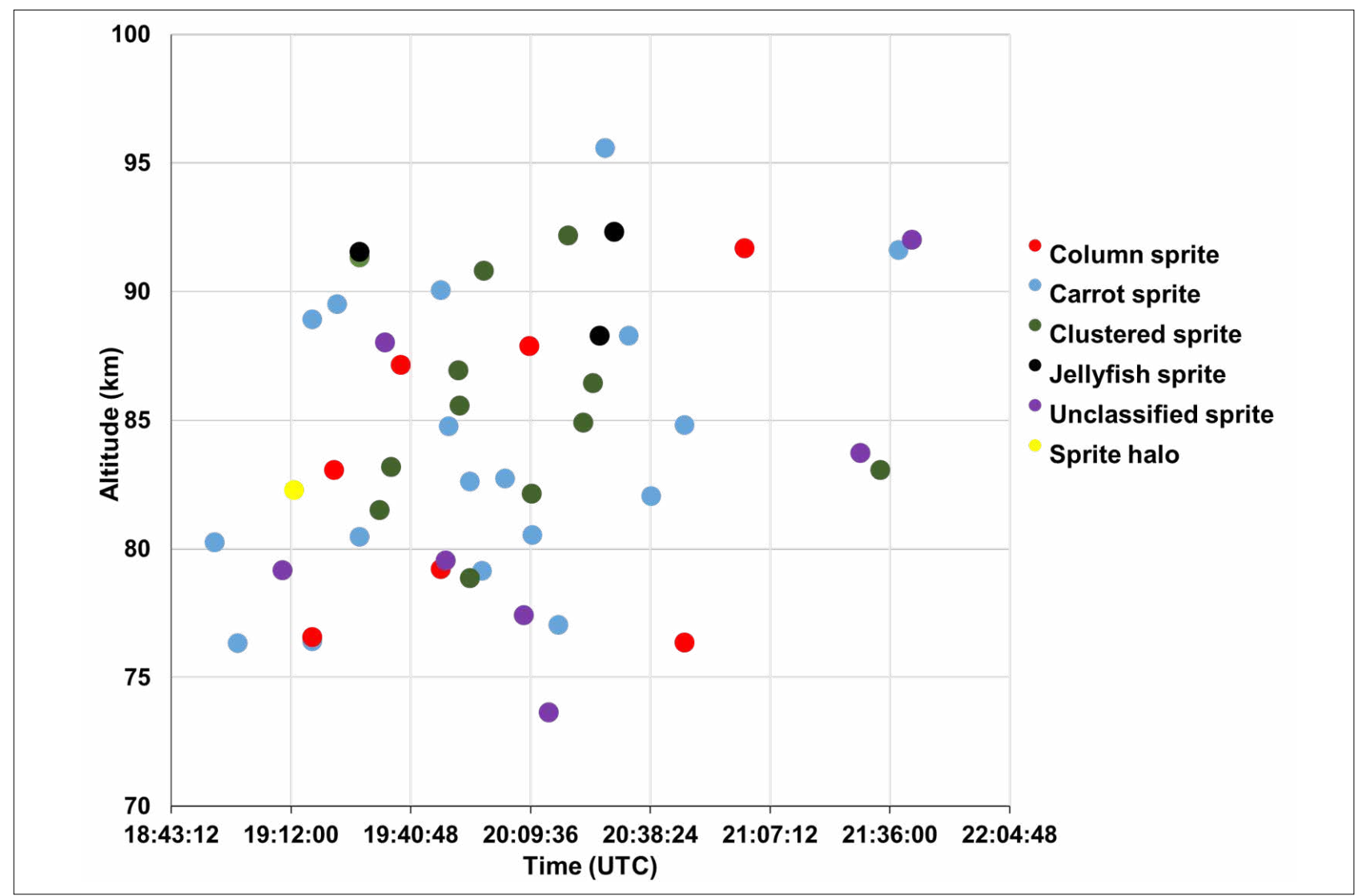

Figure 3: The top altitude of the 48 sprites with respect to the time at which they were observed during the 2016 sprites campaign.

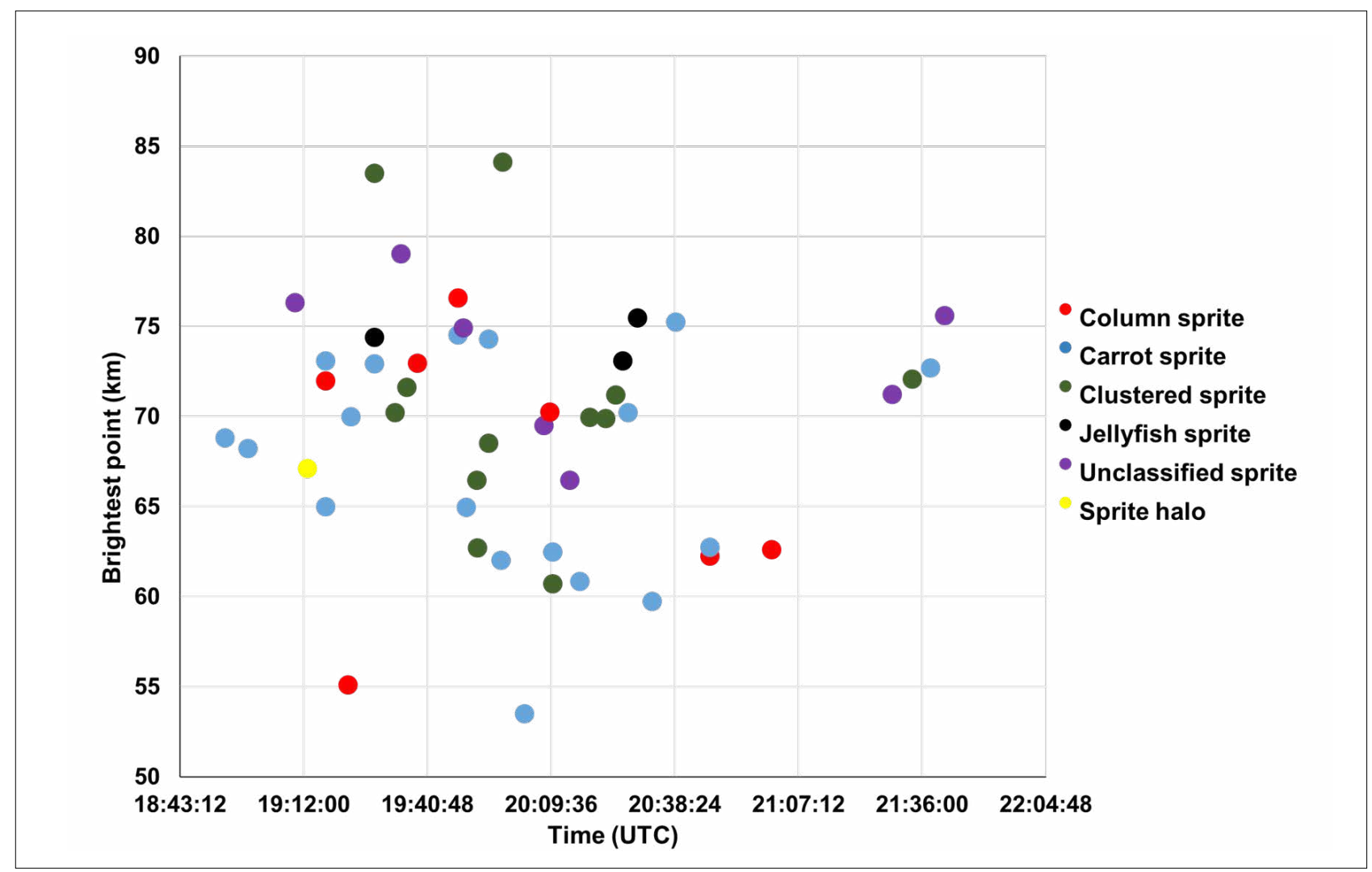

Figure 4: The altitude of maximum brightness of the 48 sprites with respect to their time of occurrence. 


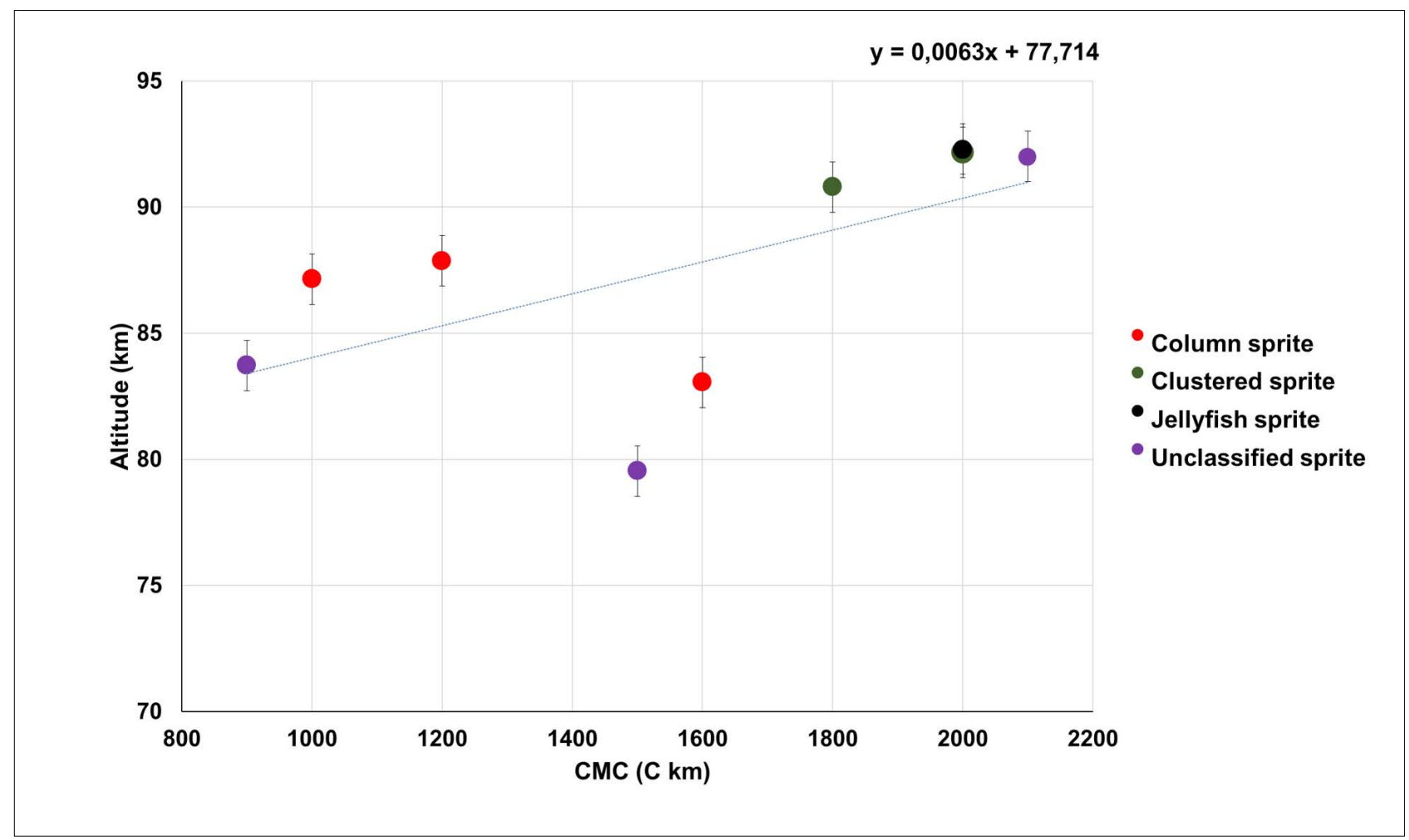

Figure 5: The relationship between charge moment change (CMC) and the top altitude of sprites.

\section{Authors' contributions}

D.C.M.: Conceptualisation, methodology, data collection, sample analysis, data analysis, validation, data curation, writing - the initial draft, writing - revisions. M.J.K.: Conceptualisation, methodology, data collection, sample analysis, validation, student supervision, project leadership, project management. J.B.: Data collection, sample analysis. S.N.: Data collection, sample analysis.

\section{References}

1. Siingh D, Singh $R$, Singh A, Kumar S, Kulkarni M, Singh A. Discharges in the Stratosphere and Mesosphere. Space Sci Rev. 2012;169(1-4):73-121. https://doi.org/10.1007/s11214-012-9906-0

2. Füllekrug $M$, Rycroft $M$. The contribution of sprites to the global atmospheric electric circuit. Earth Planets Space. 2006;58(9):1193-1196. https://doi. org/10.1186/bf03352009

3. Rycroft M, Odzimek A. Effects of lightning and sprites on the ionospheric potential, and threshold effects on sprite initiation, obtained using an analog model of the global atmospheric electric circuit. J Geophys Res. 2010;115(A6), A00E37. https://doi.org/10.1029/2009ja014758

4. Soula $\mathrm{S}$, lacovella $\mathrm{F}$, Van der Velde 0 , Montanyà J, Füllekrug M, Farges T, et al. Multi-instrumental analysis of large sprite events and their producing storm in southern France. Atmos Res. 2014;135-136:415-431. https://doi. org/10.1016/j.atmosres.2012.10.004

5. Soula S, Mlynarczyk J, Füllekrug M, Pineda N, Georgis J, Van der Velde 0, et al. Dancing sprites: Detailed analysis of two case studies. J Geophys Res Atmos. 2017;122(6):3173-3192. https://doi.org/10.1002/2016jd025548

6. Pasko V, Yair Y, Kuo C. Lightning related transient luminous events at high altitude in the Earth's atmosphere: Phenomenology, mechanisms and effects. Space Sci Rev. 2011;168(1-4):475-516. https://doi.org/10.1007/s11214011-9813-9

7. Lyons W. Sprites. Encyclopedia of atmospheric sciences. Atmos Res. 2003:3:738-747. https://doi.org/10.1016/b0-12-227090-8/00146-9
8. Yaniv R, Yair Y, Price C, Bór J, Sato M, Hobara Y, et al. Ground-based observations of the relations between lightning charge-moment-change and the physical and optical properties of column sprites. J Atmos Sol Terr Phys. 2014;107:60-67. https://doi.org/10.1016/j.jastp.2013.10.018

9. Neubert T, Allin T, Blanc E, Farges T, Haldoupis C, Mika A, et al. Co-ordinated observations of transient luminous events during the EuroSprite2003 campaign. J Atmos Sol Terr Phys. 2005;67(8-9):807-820. https://doi. org/10.1016/j.jastp.2005.02.004

10. Franz R, Nemzek R, Winckler J. Television Image of a large upward electrical discharge above a thunderstorm system. Science. 1990;249(4964):48-51. https://doi.org/10.1126/science.249.4964.48

11. Hu W, Cummer S, Lyons W, Nelson T. Lightning charge moment changes for the initiation of sprites. Geophys Res Lett. 2002;29(8):120-1-120-4. https:// doi.org/10.1029/2001gl014593

12. Nnadih S, Kosch M, Martinez $P$, Bor J. First ground-based observations of sprites over southern Africa. S Afr J Sci. 2018;114(9/10), Art. \#4272. https://doi.org/10.17159/sajs.2018/4272

13. Chen A, Kuo C, Lee Y, Su H, Hsu R, Chern J, et al. Global distributions and occurrence rates of transient luminous events. J Geophys Res. 2008;113(A8), A08306. https://doi.org/10.1029/2008ja013101

14. Sentman D, Wescott E, Osborne D, Hampton D, Heavner M. Preliminary results from the Sprites94 Aircraft campaign: 1. Red sprites. Geophys Res Lett. 1995;22(10):1205-1208. https://doi.org/10.1029/95gl00583

15. Wescott E, Sentman D, Heavner M, Hampton D, Lyons W, Nelson T Observations of 'Columniform' sprites. J Atmos Sol Terr Phys. 1998;60(79):733-740. https://doi.org/10.1016/s1364-6826(98)00029-7

16. Stenbaek-Nielsen $H$, Haaland R, McHarg M, Hensley B, Kanmae T. Sprite initiation altitude measured by triangulation. J Geophys Res. 2010;115(A3), A00E12. https://doi.org/10.1029/2009ja014543

17. Ganot M, Yair Y, Price C, Ziv B, Sherez Y, Greenberg E, et al. First detection of transient luminous events associated with winter thunderstorms in the eastern Mediterranean. Geophys Res Lett. 2007;34(12), L12801, 5 pages. https://doi.org/10.1029/2007gl029258 
18. Li J, Cummer S, Lyons W, Nelson T. Coordinated analysis of delayed sprites with high-speed images and remote electromagnetic fields. J Geophys Res. 2008;113(D20), D20206, 11 pages. https://doi.org/10.1029/2008jd010008

19. McHarg M, Stenbaek-Nielsen H, Kammae T. Observations of streamer formation in sprites. Geophys Res Lett. 2007;34(6), L06804, 5 pages. https://doi.org/10.1029/2006gl027854

20. Soula $\mathrm{S}$, Van der Velde 0 , Montanyà J, Neubert T, Chanrion 0 , Ganot M. Analysis of thunderstorm and lightning activity associated with sprites observed during the EuroSprite campaigns: Two case studies. Atmos Res. 2009;91(2-4):514-528. https://doi.org/10.1016/j.atmosres.2008.06.017

21. Gamerota W, Cummer S, Li J, Stenbaek-Nielsen H, Haaland R, McHarg $M$. Comparison of sprite initiation altitudes between observations and models. J Geophys Res. 2011;116(A2), A02317, 9 pages. https://doi. org/10.1029/2010ja016095

22. Liu N, Boggs L, Cummer S. Observation-constrained modeling of the ionospheric impact of negative sprites. Geophys Res Lett. 2016;43(6):23652373. https://doi.org/10.1002/2016gl068256

23. Gijben M. The lightning climatology of South Africa. S Afr J Sci. 2012;108(3/4), Art. \#740, 10 pages. https://doi.org/10.4102/sajs.v108i3/4.740

24. Duffett-Smith P Practical astronomy with your calculator. 3rd ed. Cambridge: Cambridge University Press; 1989. https://doi.org/10.1017/ CB09780511564895

25. Siranah.de. Applications of spherical trigonometry in navigation [webpage on the Internet]. No date [updated 2010 Dec 03; cited 2019 Nov 20]. Available from: http://www.siranah.de/html/sail042e.htm

26. Lyons W. Sprite observations above the U.S. high plains in relation to their parent thunderstorm systems. J Geophys Res Atmos. 1996;101(D23):2964129652. https://doi.org/10.1029/96jd01866

27. Mlynarczyk J, Bór J, Kulak A, Popek M, Kubisz J. An unusual sequence of sprites followed by a secondary TLE: An analysis of ELF radio measurements and optical observations. J Geophys Res Space Phys. 2015;120(3):22412254. https://doi.org/10.1002/2014ja020780
28. Bór J, Zelkó Z, Hegedüs T, Jäger Z, Mlynarczyk J, Popek M, et al. On the series of +CG lightning strokes in dancing sprite events. J Geophys Res Atmos. 2018;123(19):11030-11047. https://doi.org/10.1029/2017jd028251

29. Pasko V, Inan U, Bell T. Spatial structure of sprites. Geophys Res Lett. 1998;25(12):2123-2126. https://doi.org/10.1029/98gl01242

30. Luque A, Stenbaek-Nielsen H, McHarg M, Haaland R. Sprite beads and glows arising from the attachment instability in streamer channels J Geophys Res Space Phys. 2016;121(3):2431-2449. https://doi. org/10.1002/2015ja022234

31. Bór J. Optically perceptible characteristics of sprites observed in central Europe in 2007-2009. J Atmos Sol Terr Phys. 2013;92:151-177. https:// doi.org/10.1016/j.jastp.2012.10.008

32. Malagón-Romero A, Teunissen J, Stenbaek-Nielsen $H$, McHarg $M$, Ebert $U$, Luque A. On the emergence mechanism of carrot sprites. Geophys Res Lett. 2020;47(1), e2019GL085776, 8 pages. https://doi. org/10.1029/2019gl085776

33. Neubert T, Rycroft M, Farges T, Blanc E, Chanrion O, Arnone E, et al. Recent results from studies of electric discharges in the Mesosphere. Surv Geophys. 2008;29(2):71-137. https://doi.org/10.1007/s10712-008-9043-1

34. Füllekrug M, Nnadih S, Soula S, Mlynarczyk J, Stock M, Lapierre J, et al Maximum sprite streamer luminosity near the Stratopause. Geophys Res Lett. 2019;46(21):12572-12579. https://doi.org/10.1029/2019gl084331

35. Williams E, Lyons W, Hobara Y, Mushtak V, Asencio N, Boldi R, et al. Groundbased detection of sprites and their parent lightning flashes over Africa during the 2006 AMMA campaign. Quart J Roy Meteor Soc. 2009;136(S1):257271. https://doi.org/10.1002/qj.489

36. Ádám A, Bencze P, Bór J, Heilig B, Kis Á, Koppán A, et al. Geoelectromagnetism and the changing Earth. Acta Geod Geophys Hung. 2009;44(3):271-312. https://doi.org/10.1556/ageod.44.2009.3.3

37. Peat J, Barton B, Elliott E. Statistics workbook for evidence-based health care New York: John Wiley \& Sons; 2009 